\title{
DISEÑo PARA EL BIENESTAR HUMANO. \\ El sentido y el contenido del discurso gráfico
}

\section{Nidia Raquel Gualdrón Cantor*}

\section{Resumen}

En el artículo se construye un marco de referencia del diseño gráfico para el bienestar humano, como campo y escenario de investigación. Su abordaje se realizó desde el contenido, la naturaleza de la acción. Para sus efectos, se elaboró una revisión de conceptos, perspectivas y reflexiones privilegiando autores latinoamericanos y se propusieron categorías desde las cuales pensar los alcances y posibilidades del diseño gráfico en la sociedad contemporánea, en las esferas de lo cotidiano y lo público, considerando las implicaciones funcionales, cognitivas, políticas y emocionales con las que pueden trascender los procesos, los discursos y los artefactos visuales. Como discusión, se señalan algunos aspectos sobre los que se invita a reflexionar en el ejercicio de la profesión en el entorno productivo como también en el académico.

Palabras clave: diseño gráfico, bienestar humano, diseño consciente, diseño responsable, diseño positivo, diseño centrado en las personas.

\section{Recibido: Julio 18, 2017 - Aceptado: Noviembre 21, 2017}

*Diseñadora gráfica por la Universidad Nacional de Colombia (1999); Especialista en Pedagogía del diseño por la Universidad Nacional de Colombia (2011). Maestrante en E-Learning en la Universidad Popular Autónoma del Estado de Puebla, [Mx.] (actualmente). Experiencia profesional en la industria editorial para el sector público y privado; docente de espacios académicos como Diseño de medios editoriales en la Universidad de Bogotá Jorge Tadeo Lozano, Diseño para sistemas de información y orientación, Tipografía, y Diseño y Contextualización visual en los Programas de Diseño Gráfico y Comunicación Social en la Fundación Universitaria Los Libertadores, en Bogotá Colombia. Adscrita también en esta institución como docente investigadora, líder del Semillero de investigación Gráfica para el bienestar humano y gestora curricular. Orcid. https://orcid.org/0000-0003-3003-2874 ;

Email: nrgualdronc@libertadores.edu.co ; caligrafe@gmail.com

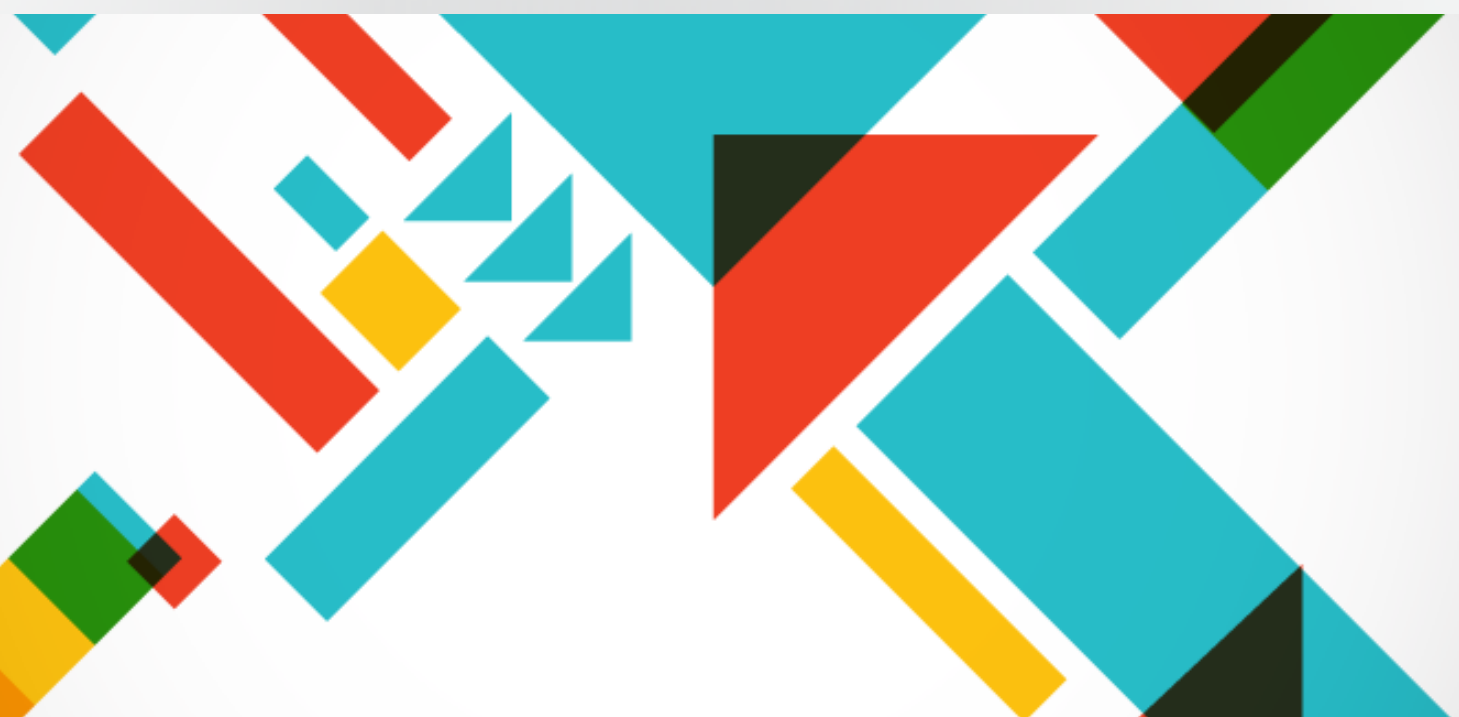




\section{DESIGN FOR HUMAN WELFARE. The meaning and content of graphic discourse}

\section{Summary}

This document intends to make a frame of reference for the graphic design for human welfare, as field and research. Its approach is made from the content, the nature of the action and not from the products or the domains of the visual language. For its effects, a revision of concepts, perspectives and reflections was developed favoring latin american authors, and categories were proposed to think about the goals and graphic design possibilities in contemporary society, in the public and daily spheres, considering the functional, cognitive, political and emotional implications with which it is possible to emerge the processes, speeches and visual artifacts. As a discussion, some aspects are mentioned that are invited to reflect on the practice of the profession in the productive environment as well as in the academic.

Keywords: graphic design, human well-being, conscious design, responsible design, positive design, human-centered design

Received . July 18, 2017 - Accepted. November 21, 2017

\section{\#Yosoydiverso (Eusoudiverso) Estrategia transmedia de comunicação}

\section{Resumo}

No artigo uma marca de referência é construída para o desígnio gráfico para o bem-estar humano, como campo e cenário de investigação. A análise foi levada a cabo desde o conteúdo, a natureza da ação e não desde os produtos nem desde os domínios do idioma visual. Para seus efeitos foi elaborado uma revisão de conceitos, perspectivas e reflexões privilegiando autores latinoamericanos e se propuseram categorias desde as quais pensar os alcances e possibilidades do projeto gráfico na sociedade contemporânea, nas esferas do quotidiano e o público, considerando as implicações funcionais, cognitivas, políticas e emocionais com as que podem transcender os processos, as falas e os dispositivos visuais. Como discussão, se assinalam alguns aspectos sobre os que se convida meditar no exercício da profissão no ambiente produtivo como também no acadêmico.

Palavras chaves: projeto gráfico, bem-estar humano, desígnio (projeto) consciente, projeto responsável, projeto positivo, projeto centrado nas pessoas

Recebido: Julho 18, 2017 - Aceitado. Novembro 21, 2017 


\section{INTRODUCCIÓN}

El diseño es el ecualizador universal. Cuando se hace de manera eficaz y con integridad, proporciona valor estético, económico, social y cultural".

Don Ryun Chang (Seúl)

Presidente de Icograda 2009-2011

Los años 1990 se cerraron con el First Things First Manifesto 2000, que dio lugar a un interesante debate sobre el compromiso y la responsabilidad de la profesión.

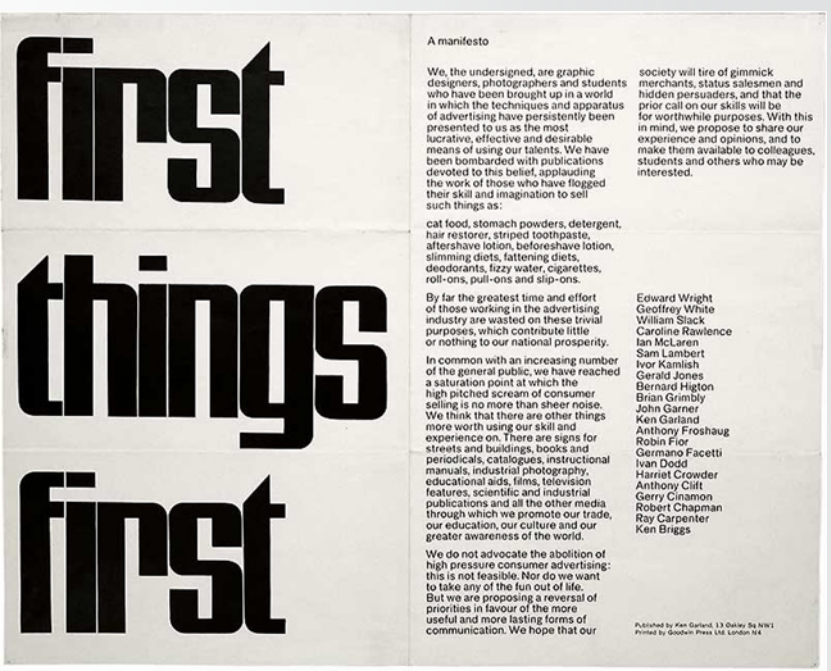

"Los diseñadores gráficos tienen una posición privilegiada dentro de la cultura contemporánea, al tratar con el arte, el comercio y la ciencia en el medio impreso, en la pantalla o en la esfera pública. Es un papel que requiere responsabilidad [...]" (Pelta, 2015, pág. 13).

Se trajo de nuevo a la agenda [1] el entrañable compromiso de practicar un diseño consciente que supone ser sensible al contexto, dar prioridad a la entidad humana, tratar el "contenido" como algo que hacemos y no como algo que vendemos, concebir las diferencias culturales como valores positivos y no como obstáculos y centrarse en los servicios más que en las cosas, para no inundar el mundo con artefactos carentes de sentido.

Desde esta perspectiva, innumerables reflexiones se han suscitado desde, hacia y por el diseño en su relación co, inter, trans y meta con las ciencias, disciplinas y campos que se articulan en función de este interés considerando el impacto del diseño en el pensamiento, la práctica, la cultura, la economía y en general, en la vida de las personas. Sin embargo, de acuerdo con Tony Fry: como tampoco lo están dentro de la cultura política e intelectual. Así lo demuestra, por ejemplo, el que los profesionales se muestren bastante remisos a aceptarla -hacerlo supondría tanto como asumir la responsabilidad social que conlleva-" (Pelta, 2012).

En el ejercicio docente y ante el llamado de las propias dinámicas proyectuales del diseño gráfico, aceptar esa responsabilidad empieza por preguntarse de qué se trata este desafío, cuáles son sus premisas conceptuales, quiénes son las voces, cuáles sus aproximaciones metodológicas y cómo categorizar sus alcances y variables, para construir un marco de referencia desde el cual encararlo. Es satisfactorio encontrar que en el entorno latinoamericano cada vez más autores coinciden en estos cuestionamientos y profundizan desde diversas vertientes compartiendo sus hallazgos y experiencias.

Enconsecuencia, elcontenidoqueaquí se presenta es un sistema de coordenadas y relaciones desde los propios intereses profesionales y académicos que empiezan por abordar de manera general dos grandes conceptos: la relación diseño / bienestar humano y la responsabilidad del diseño gráfico considerando cuatro aspectos: 1) el diseño para la realización personal y las relaciones entre las personas, 2) el diseño para la relación personas entornos, territorios; 3) el diseño para la relación personas - interfaces, mensajes, productos; y 4) el diseño gráfico en la investigación centrada en las personas.

Esta reflexión se suscita desde el fenómeno, el saber, la esencia, la acción. Como dice Pelta (2015, pág. 21) "los resultados formales son casi siempre el reflejo de las ideas" y la gráfica es la capa visible de un constructo ideológico sustentado en procesos y experiencias. Al respecto Chaves afirma:

La gráfica no es un invento del diseño sino un campo de la cultura, milenario, previo incluso a la arquitectura. En el cronograma de la historia de la gráfica, el diseño ocupa un segmento imperceptible. El diseño gráfico hereda esos milenios y los pone en acción. El diseño gráfico es la creación de mensajes gráficos mediante los códigos de la comunicación gráfica, códigos que lo preceden y lo exceden (2016, pág. 16). "esa omnipresencia y su importancia pasada, presente y futura, todavia no están suficientemente reconocidas ni siquiera por parte de los profesionales del diseño 


\section{DISEÑO Y BIENESTAR HUMANO}

Desde el movimiento Arts and Crafts, surgido en Inglaterra a mediados del siglo XIX, que crea una filosofía basada en el ser humano y en su bienestar, el interés por vincular el diseño y el bienestar humano ha estado presente. El diseño verde, el diseño responsable, el consumo ético, el ecodiseño, la sustentabilidad y el diseño feminista se han visibilizado en mayor proporción a partir de la década de los 1960s.

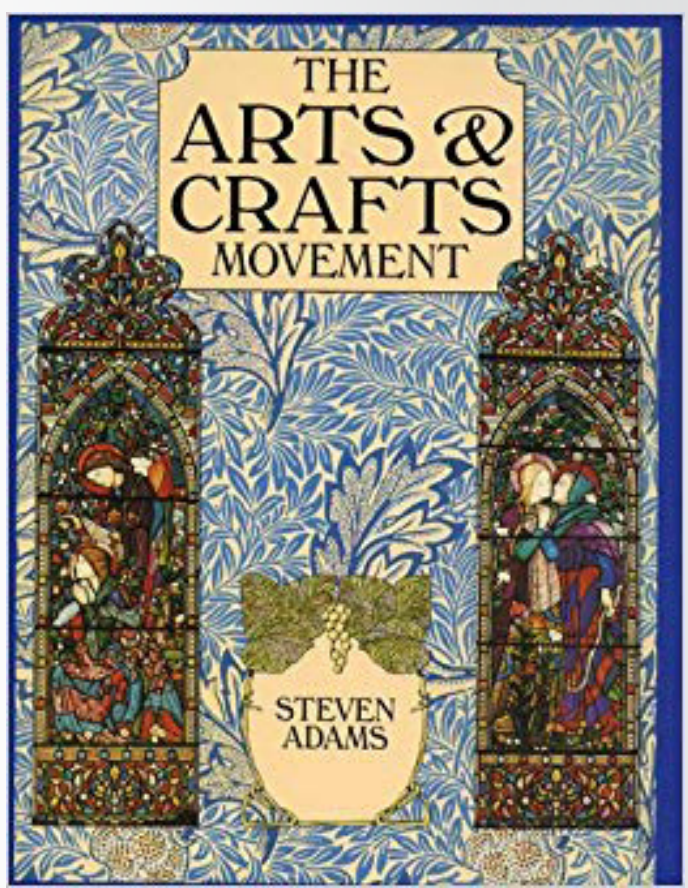

En 1963, p.e. Ken Garland junto con 20 diseñadores, fotógrafos y estudiantes en Gran Bretaña produjeron un manifiesto al que llamaron First-things-first, rechaza las producciones de ritmo rápido y a menudo triviales de la publicidad convencional, y aboga por centrar los esfuerzos de diseño en las tareas de educación y los servicios públicos que promueven la mejora de la sociedad [2]. Reeditado por grupos de nuevos autores en los años 2000 y 2014, es un referente de cómo el diseño, con un reconocido liderazgo del industrial, desde hace pocas décadas ha tenido esa perspectiva autocrítica, en la línea del diseño socialmente responsable, o lo que para la presente reflexión se considera diseño para el bienestar humano.

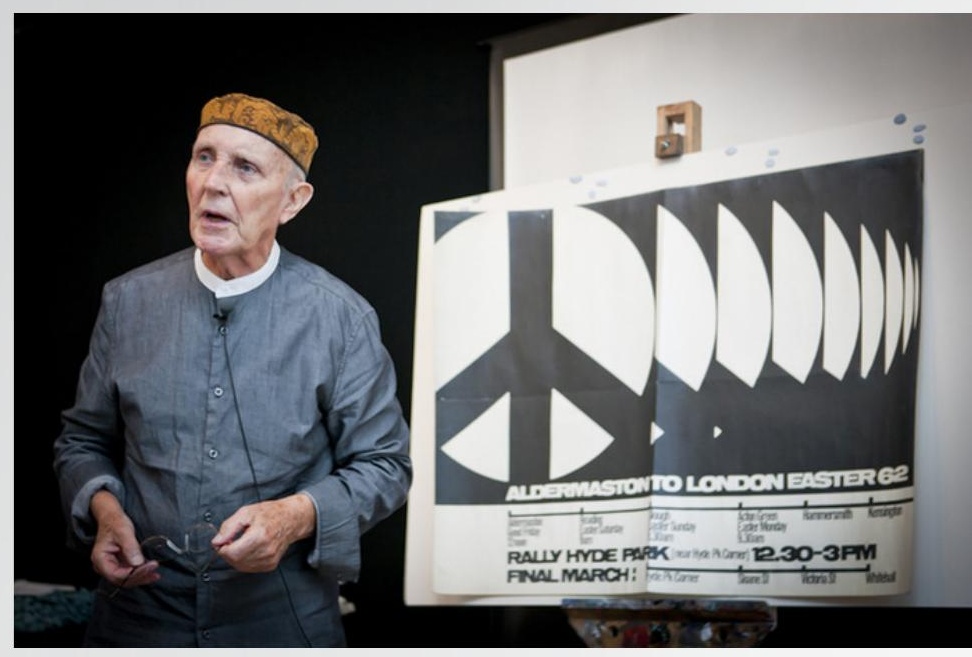

Ken Garland

El término bienestar, en el Diccionario de la Real Academia Española, viene de "bien" y "estar", en referencia al estado de la persona en el que es sensible al buen funcionamiento de su actividad somática y psíquica, es una situación de satisfacción o felicidad. El bienestar humano, definido de manera genérica es el estado en que las personas tienen la capacidad y la posibilidad de llevar una vida que tienen motivos para valorar, implica tener seguridad personal y ambiental, acceso a bienes materiales para llevar una vida digna, buena salud y buenas relaciones sociales, todo lo cual guarda una estrecha relación con la libertad para tomar decisiones y actuar.

El diccionario Akal de economía moderna (1999) considera el bienestar como un concepto ético porque afirmar que, hacer un juicio de valor, algo aporta al bienestar. Para fines del presente documento, este concepto se ubica en torno a la experiencia humana en relación con los productos de diseño gráfico [3], desde su función de mediador, facilitador o potenciador del bienestar de las personas. Hablar entonces de diseño para el bienestar humano implica por lo menos dos condiciones fundamentales: lo que significa el bienestar de las personas, es decir, los principios fundamentales para sus experiencias positivas y el diseño -también hecho por personas-, como mediador o como detonador de esas experiencias y como potenciador de actos responsables con las personas y sostenibles con el entorno natural y cultural. 


\subsection{EL DISEÑO SOCIALMENTE RESPONSABLE}

(Barrera \& Quiñones, 2009), se aproximan al concepto de diseño socialmente responsable como "la capacidad para abordar problemas fundamentales y prioritarios de la sociedad a nivel integral, no solamente los derivados de las exigencias marcadas por las dinámicas del mercado, a partir de lo cual se plantean formulaciones de proyectos de diseño que consideran los intereses de todas las personas involucradas en las problemáticas planteadas, que asumen un compromiso con la sociedad y la naturaleza, que se responsabilizan por las consecuencias de las decisiones, acciones y resultados a nivel social, económico y ambiental, y que concretan estrategias de transformación social en la búsqueda de bienestar integral. A nivel de resultados, se puede entender que comprende las respuestas proyectuales creativas y pertinentes, y los productos que genera el diseñador con las comunidades o poblaciones objetivo.

Las reflexiones que contiene este documento abordan desde diferentes perspectivas la responsabilidad del diseñador gráfico en las dinámicas socio-culturales, que aunque no son las únicas, son un segmento relevante en la configuración de la noción "diseño socialmente responsable".

Si los que pertenecemos a la comunidad del diseño vamos para proponer escenarios para el cambio social, debemos responder dos preguntas: primero, cómo desarrollar un conjunto de valores básicos que puedan orientarnos para juzgar la forma en que nos gustaría que el mundo fuera; y segundo, cómo aprender a ver más allá del engaño del orden al que Morris se refirió, para entender el verdadero carácter de los dispositivos, de los sistemas y situaciones con y dentro de los cuales vivimos. (Margolin, El diseñador ciudadano, 2009).

\subsection{LA USABILIDAD}

El término usabilidad que por convención cultural se entiende por "cualidad de ser usable" y por tanto se refiere a "algo" susceptible de ser usado, en esencia es un concepto que ha sido aplicado al diseño en cualquiera de sus tipologías y medios de producción, desde el mismo momento en que se haya considerado con un propósito para el uso humano. Aunque pareciera que proviene del medio digital como parte de la "rueda de la experiencia de usuario", se relaciona en el amplio espectro de las interfaces gráficas con conceptos como utilidad, facilidad de uso, facilidad de aprendizaje y apreciación en términos de accesibilidad, diseño de información, buscabilidad, arquitectura de información y diseño de interacción.

De hecho, los problemas de usabilidad -lejos de pertenecer únicamente a los entornos digitalesse presentan con considerable frecuencia en las tareas más comunes y cotidianas de nuestra interacción con el mundo, que es cada vez más complejo.

\begin{abstract}
"Cualquier experiencia o proposición compleja es un desafío para el diseño [...]. En realidad, el mensaje que implique tres o más niveles de información, o interfase que implique tres o más niveles de selección u objeto cuyas características físicas no induzcan naturalmente al mejor cumplimiento de una función (un concepto conocido como affordance, en inglés) son ya desafíos para la usabilidad". (Stolarski, 2009, pág. 86)
\end{abstract}

De Valle (2009) propone desde la perspectiva amplia del diseño gráfico un análisis de las relaciones usabilidad / percepción; usabilidad / hermenéutica, usabilidad / comunicación, usabilidad/medio digital, usabilidad/antropología, para generar el debate sobre la consideración de la usabilidad aplicada a la noción de diseño centrado en el usuario en tanto media y potencia las diversas interacciones entre las personas y las interfaces que la relacionan con su entorno particular, con atención a los significados y valores que estas adquieren en esa mediación. Por ende, la usabilidad es condición en la determinación del diseño como proceso de comunicación y parte de identificar conscientemente las diferentes percepciones e interpretaciones de las personas en su relación con objetos, mensajes y lugares para diseñar experiencias con las cualidades que generen su bienestar.

\subsection{EL DISEÑo POSITIVO}

Sustentado en los principios de la psicología positiva [4], emerge el diseño positivo como una estrategia de innovación que promueve generar experiencias significativas en los usuarios, en su interacción con los artefactos o interfaces que los conectan con los diferentes entornos. Persigue esencialmente el bienestar psicológico y felicidad a largo plazo, por medio de la aplicación práctica del conocimiento derivado de la investigación en ciencias sociales: psicología positiva, psicología 
emocional y economía conductual (Jiménez, Pohlmeyer, \& Desmet, 2016). Tan es así, que se ha creado desde 2011 en el Delft Institute of Positive Design [5], con el propósito de "iniciar y estimular el desarrollo de conocimiento que apoya los diseñadores en sus intentos de diseñar para la felicidad, para el florecimiento humano".

Según el Instituto, este conocimiento no solo debe ayudar a los profesionales en sus intentos de diseñar para las relaciones producto-usuario significativas, sino en última instancia también para diseñar productos que contribuyen a una sociedad saludable: hacer del mundo un lugar mejor. Estos avances, son evidentes principalmente en el diseño industrial, aun cuando la perspectiva sea interdisciplinar.

El marco conceptual del diseño positivo introducido por Pieter Desmet y Anna Pohlmeyer (2013), se reduce a tres componentes principales de diseño para el bienestar de las personas, establecidos desde la psicología positiva y la filosofía: placer, significado personal y virtudes, en los cuales su alcance, énfasis metodológicos y resultados son variantes desde las cuales el diseño se aproxima. Los autores especifican cinco características del diseño positivo que tienen implicaciones importantes para el proceso de diseño: impacto a largo plazo en las vidas de las personas, encontrar un balance entre el placer y el significado, metas a corto y largo plazo e intereses individuales y sociales, enfocarse en posibilidades de diseño no inmediatas sino a través del reconocimiento de los usuarios potenciales y de su contexto, proceso que se enriquece cuando estos se involucran de forma activa para lograr el efecto deseado.

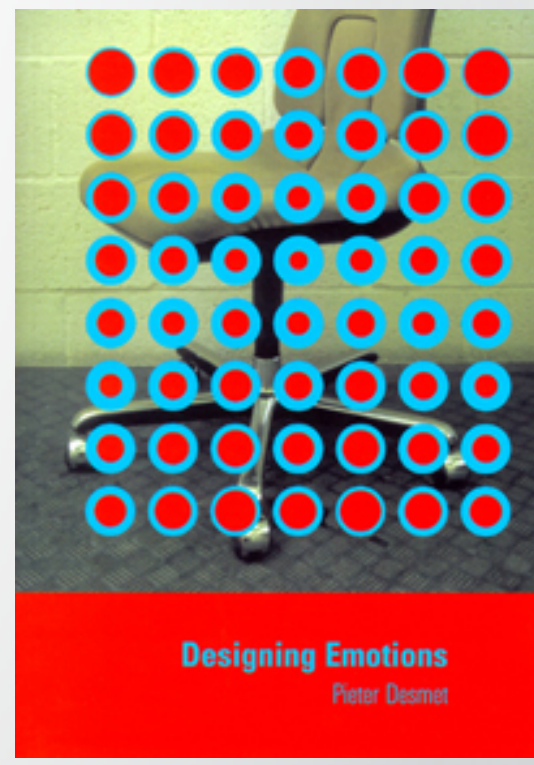

\subsection{EL PENSAMIENTO DE DISEÑO}

Desde el punto de vista de la pragmática, el pensamiento de diseño es en esencia un proceso metodológico que propende por la innovación y se centra en las personas, haciendo hincapié en la observación, colaboración, aprendizaje rápido, prototipado rápido, validación de propuestas y análisis de negocio iterativo.

Este tipo de dinámica integra personas, técnicas y herramientas, bajo los principios de empatía en la comprensión del problema, desde sus diferentes aristas y condicionantes, creatividad a la hora de generar ideas y visualizar soluciones, eficiencia en los procesos, medios y herramientas de trabajo y eficacia en los prototipos, los testeos y la ejecución del proyecto; lo que sitúa al diseño en un lugar integrador de experiencias, retomando diferentes aportes de las ciencias sociales, la ingeniería y el mundo de las ciencias administrativas. Esta mezcla permite centrar la atención en el usuario final y sus deseos o necesidades, más que en la forma de los artefactos, lo que mejora significativamente la producción de sistemas, productos y servicios innovadores (Castellanos \& Otros, 2017)

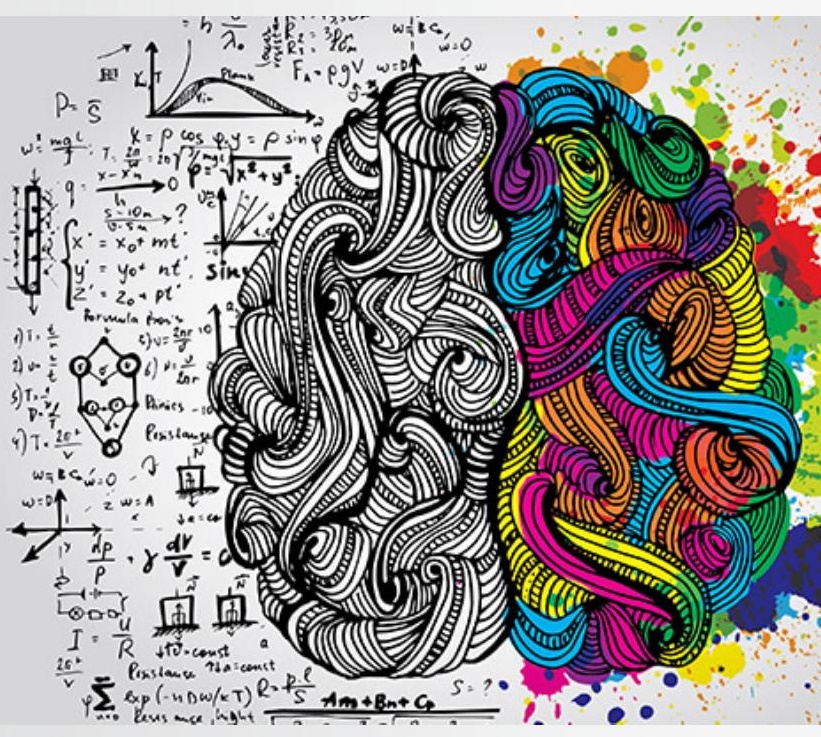

Los autores en los campos de la innovación favorecen una visión del diseño en la que no solamente aporta a "solucionar problemas" minimizando lo que molesta a las personas en la vida cotidiana, sino que le apuestan al diseño como motor de la prosperidad económica, social, cultural y como un motor de posibilidades 
(Jimenez, Pohlmeyer, \& Desmet, 2014). Tim Brown (IDEO.org, 2015) al proponer el paso del diseño al pensamiento de diseño - design thinkingse arriesga a que las ideas se traduzcan en productos y servicios en beneficio de las personas y resalta desde esta perspectiva una responsabilidad de los diseñadores mucho mayor que abordar una insuficiencia.

Amplia es la variedad de teorías y marcos conceptuales que revelan desde esta perspectiva oportunidades y vías de diseño para el bienestar humano.

\subsection{LA RESPONSABILIDAD DEL DISEÑO GRÁFICO}

Desde sus orígenes, la actividad del diseño gráfico ha sido un eslabón en el proceso industrial al que se le atribuiría la incorporación de la dimensión artística para agregar valor estético a los productos y servicios de consumo. Sin embargo, su creciente presencia en todas las actividades humanas puede tornarse vacía y hasta cómplice de las consecuencias de la saturación y la masividad, cuando se piensa en sí mismo como fin y no en su contexto de uso, es decir, en la interacción comunicativa de la que forma parte. Por décadas, las reflexiones teóricas se han centrado en la forma y posteriormente en la función, pero todos sus aspectos semánticos, sintácticos, estéticos o técnicos solo adquieren sentido cuando se centran en las personas y en los efectos que en ellas producen, es decir, cuando trascienden en la dimensión personal, social y cultural.

En efecto, el diseño está en todas partes: en la imagen de los productos, en los sistemas de lectura, en los espacios habitables, en las llamadas realidades virtuales y en el ciberespacio pero, al mismo tiempo, es el principal generador de la basura que rodea a las ciudades y de la banalidad de los contenidos que definen buena parte de nuestro universo cultural. (Tapia, 2005, pág. 11)

Desde una perspectiva afin, Betancourt (2014) afirma que más que una "práctica operativa estetizante" ligada a las necesidades y exigencias de un cliente, el diseño gráfico debe poder solucionar desde su discurso disciplinar los retos que enfrenta siendo capaz de nutrirse de diversas disciplinas y saberes y a su vez de contribuir al restablecimiento de las mediaciones entre los contextos reales naturales y artificiales, los objetos y los sujetos, que favorezcan las miradas críticas y transformadoras con acciones que garanticen un desarrollo social sostenible. En Diseño gráfico para la gente, Frascara (2008) sostiene que el
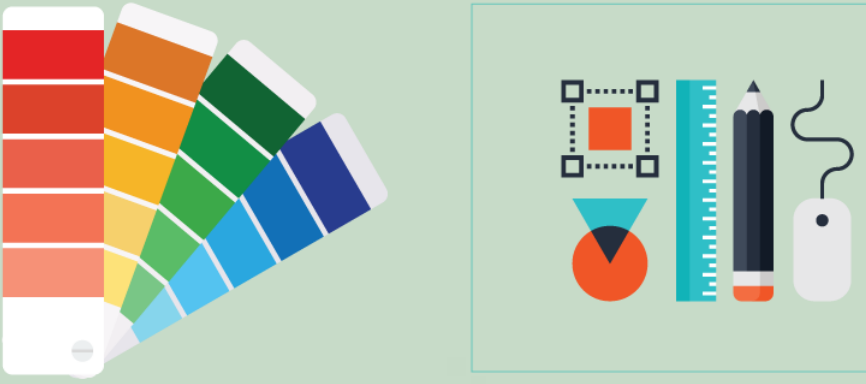

acto de dar forma incluye al menos cuatro áreas distintas de responsabilidad:

Responsabilidad profesional del diseñador frente al cliente y al público, de crear un mensaje que sea detectable, discriminable, atractivo y convincente; responsabilidad ética: la creación de mensajes que apoyen valores humanos básicos; responsabilidad social: la producción de mensajes que hagan una contribución positiva a la sociedad o, al menos, que no importen una contribución negativa, y la responsabilidad cultural: la creación de objetos visuales que contribuyan al desarrollo cultural más allá de los objetivos operativos del proyecto.

González Solás considera que "el diseño es la interfaz entre el hombre y el mundo; es el enlace, el soporte y el mensaje de la urdimbre de relaciones y proyectos sociales" y por lo mismo, es preciso que se concentre en el proyecto de sociedad y en la jerarquía de sus necesidades (2006). En los múltiples escenarios del diseño pues "es acción, que se desarrolla a partir de metodologías y procesos; es sujeto, mediante la denominación de la materialización o concreción de productos y es herramienta, al ser el medio de ayuda en diferentes procesos" (Ramírez, Lecuona, \& Cardozo, 2012), su propósito es incidir sobre el conocimiento, las actitudes, los sentimientos y/o las acciones de las personas en una manera prevista. 


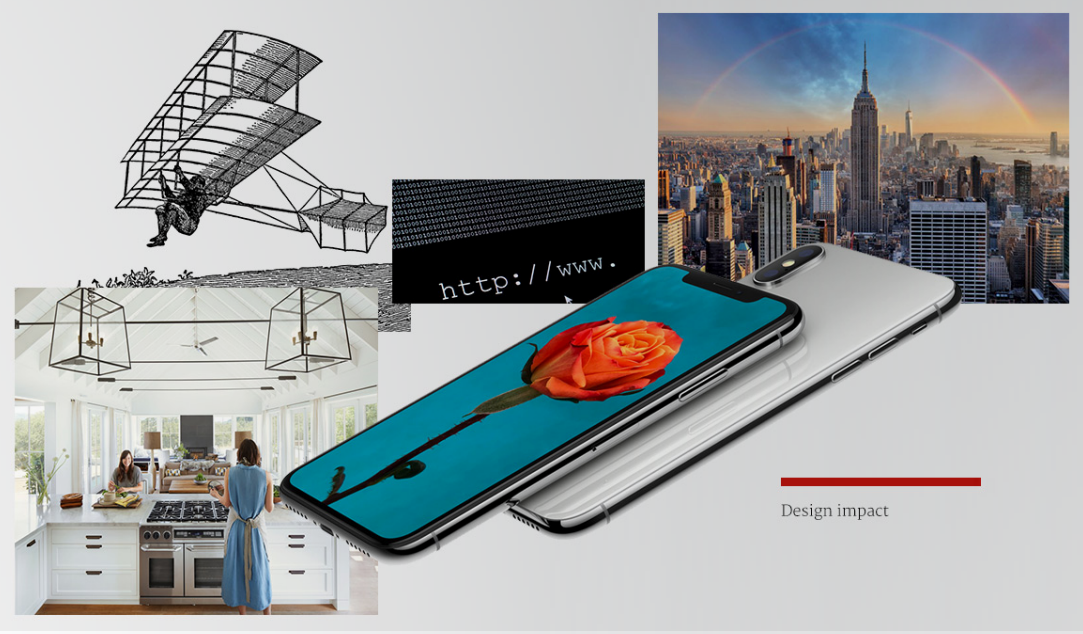

a la comprensión como a una retórica que privilegia la persuasión. Ambas disciplinas estarían en cierto modo vinculadas entre sí y serían correlatos en cualquier acto de diseño (Hernández, 2009).

\subsection{LA ACADEMIA}

El American Institute of Graphic Arts -AIGA- Asociación Profesional para el Diseño en Estados Unidos, realizó en 2015 un estudio de tendencias y competencias para determinar cuáles serían las expectativas puestas en los diseñadores del

Los objetos materiales, los bienes simbólicos, las interfaces, las redes y sistemas, los proyectos y los discursos, denominados "artefactos" y categorizados así por el diseñador alemán Klaus Krippendorff, son en mayor o menor medida productos del diseño y en particular del diseño gráfico, que se insertan en los espacios privados y públicos creando hábitos cognitivos y concenso cultural, ya que influyen en la manera en que las personas se relacionan entre sí, con la información y con el entorno.

Un diseño autoritario fomenta la creación de un público sumiso o autoritario. Un diseño respetuoso de la gente, fomenta el respeto de unos a otros. Un diseño que invita a pensar, invita al público a pensar por sí mismo. De esta manera, la tarea del diseñador no es solo la de facilitar la gestión de la vida cotidiana, sino también la de educar a través de la promoción de ciertas estructuras visuales que están asociadas a sistemas de valores. (Frascara, 2011).

El diseño gráfico entendido como una acción a través de la cual se crean discursos visuales que estarían sujetos tanto a la interpretación como a la traducción de la intencionalidad comunicativa del usuario por parte de quien diseña, es un acto de naturaleza hermenéutica y como tal implica las tres dimensiones: interpretación, traducción y comprensión, fases procesales del modelo: autor-texto-lector.

El producto de diseño gráfico es referido como un texto, en una dimensión más amplia que la de mensaje. El texto es un artificio cultural que puede y debe ser sujeto de una interpretación y no debe ser visto solo como un vehículo de información susceptible de ser codificada. (Alvarez, 2009, pág. 107).

De este modo, un diseño pensado como un discurso visual abierto a la interpretación, plantea la posibilidad tanto para una hermenéutica que aspire futuro, como aporte para descubrir los desafíos de las instituciones educativas. Concluyó entonces, un listado de competencias que se espera desarrollen los diseñadores (AIGA, 2015) [6], de las cuales llama la atención el cambio de paradigma del diseño-forma al diseño-contextousuario y el diseño-arquitectura de información, privilegiando ética y contextos socio culturales en la práctica del diseño.

- Amplia comprensión de las cuestiones relacionadas con los contextos cognitivos, sociales, culturales, tecnológicos y económicos para el diseño.

- Capacidad para responder a contextos de audiencia que reconozcan los factores físicos, cognitivos, culturales y sociales que dan forma a las decisiones de diseño.

- Comprensión de la ética en la práctica.

- Comprensión de los elementos anidados incluyendo causa y efecto; capacidad para desarrollar criterios de evaluación de proyectos que tengan en cuenta la audiencia y el contexto.

En la mísma línea, Nasad [7] (National Association of Schools of Art and Design, 2016, pág. 118) propone un listado de competencias que debiera desarrollar la academia en los diseñadores gráficos, entre las que están:

- Capacidad para incorporar la investigación y los hallazgos 
sobre personas y contextos en la toma de decisiones de diseño de comunicación.

- Capacidad para enmarcar y conducir investigaciones en términos de personas, actividades y sus entornos, incluyendo, -pero no limitado- el uso de métodos apropiados para determinar los deseos, necesidades y patrones de conducta de la gente y desarrollar respuestas de diseño que respeten las normas sociales y culturales entre los usuarios del diseño en contextos locales y globales.

\subsection{DISEÑO PARA LA REALIZACIÓN PERSONAL Y LAS RELACIONES ENTRE LAS PERSONAS}

La realización personal y las relaciones humanas tienen que ver a grandes rasgos con dimensiones del bienestar psicológico caracterizadas en seis componentes: la autoaceptación, las relaciones positivas con los demás, la autonomía, el dominio del entorno, el propósito en la vida y el crecimiento personal [8] (Jiménez, Pohlmeyer, \& Desmet, 2016, pág. 27). En estas dimensiones, para los intereses del diseño gráfico se propone instalar conceptos como la identidad-individual y colectiva-, la memoria y la comunicación, como elementos que cohesionan desde la experiencia humana el entorno sociocultural [9].

En Learning from the positive: a structured approach to possibility-driven design, Jiménez y Pohlmeyer (2014) exponen cómo el diseño tradicional se enfoca principalmente en situaciones actuales "desagradables" que denominamos "problemas" y en prever un futuro ideal donde se resuelvan esas situaciones. Aunque naturalmente este enfoque aumenta la calidad y eficacia de los productos y servicios, le apuestan desde las teorías y experiencias del diseño positivo a pensar en que la solución de estos problemas cotidianos no significa necesariamente entregar una experiencia positiva y valiosa y abre una nueva perspectiva sobre el papel del diseño, pues afirman que es una disciplina con el potencial de cambiar nuestro entorno y dar forma a nuestras sociedades, así que entenderlo exclusivamente como una forma de reducir las deficiencias podría limitar su potencial, si puede enriquecerse impulsado por una visión optimista de la vida cotidiana.

Por fortuna, esta dinámica interdisciplinar que ha desafiado al diseño gráfico de hace algunas décadas, ha enriquecido sus posibilidades con constructoscomoelmismodiseñopositivo, eldiseño emocional, el diseño socialmente responsable, el diseño de experiencias y la experiencia de usuario, la usabilidad y enfoques que privilegian la entidad humana en la generación y adaptación visual de contenidos que con diferentes objetivos, medios y mediaciones fluyen en el entorno social. Y como actos sociales la identidad, la memoria y la comunicación moldean la cultura, en tanto "el sistema de mitos, ritos y fetiches que componen el patrimonio de una comunidad y regulan sus comportamientos para garantizar su cohesión y continuidad histórica mediante la instauración de una identidad colectiva estable" (Chaves, El oficio de diseñar: propuestas a la conciencia crítica de los que comienzan, 2001, pág. 78)

Es pertinente mencionar de nuevo el concepto diseño-social, donde aparecen diferentes enfoques: social en tanto los actos sociales de reunión-comunión de varias personas; social referido a las redes sociales más en un territorio virtual que real, social como sinónimo de solidario, vinculado a lo moral o a lo ético que respalda la equidad por encima de los intereses individuales, y diseño social, el que satisface las necesidades humanas atendiendo a sus requerimientos reales de las personas (Ramírez, Lecuona, \& Cardozo, 2012).

La identidad de las personas, comunidades, territorios, entidades, productos y servicios se construye a través de los elementos que las diferencian de otros, caracterizables mediante el diseño de recursos visuales y visibles mediante estrategias de comunicación de los mismos. El diseño actúa aquí como revelador de aquellos elementos de identidad, como traductor a códigos visuales y como dinamizador de las relaciones identitarias que se manifiestan entre las personas, objetos y entornos. 


\subsection{IDENTIDAD Y MEMORIA}

La identidad de las personas, comunidades, territorios, entidades, productos y servicios se construye a través de los elementos que las diferencian de otros, caracterizables mediante el diseño de recursos visuales y visibles mediante estrategias de comunicación de los mismos. El diseño actúa aquí como revelador de aquellos elementos de identidad, como traductor a códigos visuales y como dinamizador de las relaciones identitarias que se manifiestan entre las personas, objetos y entornos.

Betancourt (2014) expone que el reconocimiento de diversas identidades por parte del diseñador gráfico abre el campo de acción y vislumbra claramente un camino poco recorrido que llama la atención sobre los objetivos no tradicionales del diseño dentro de la sociedad: las culturas, personas, los colectivos y organizaciones sociales usan y a su vez necesitan de elementos visuales que se convierten en signos de identificación que simbolizan y comunican su personalidad, costumbres, acciones e intenciones futuras. Citando a Bermejo, menciona que "Lo nombrado suele también necesitar ser visto, ser imaginado, encontrar la imagen que establezca con esa realidad vínculos de representación que hablen de identidad". El diseño logrado con estos fines puede entrar en diálogo social para la visibilización, la dignificación y el desarrollo colectivo, incluso ser un punto de partida para la generación de políticas públicas.

El diseño gráfico en general y específicamente el diseño de identidad visual se inscriben en un contexto social determinado por sujetos y sus modos de ser y hacer que ayudan a reconocer la cultura como algo representativo e incluyente (Betancourt, 2014). Por esto, asumirlo únicamente desde la perspectiva comercial limita las oportunidades del diseño para el bienestar de las personas pues se torna indiferente a estas demandas de consolidación de auténtica identidad [10], especialmente en individuos y comunidades que parecen invisibles en la red de relaciones contemporáneas por diversas razones entre ellas la pobreza, el acceso deficiente a la conectividad de internet, las condiciones derivadas de los sucesos sociopolíticos, entre otros.

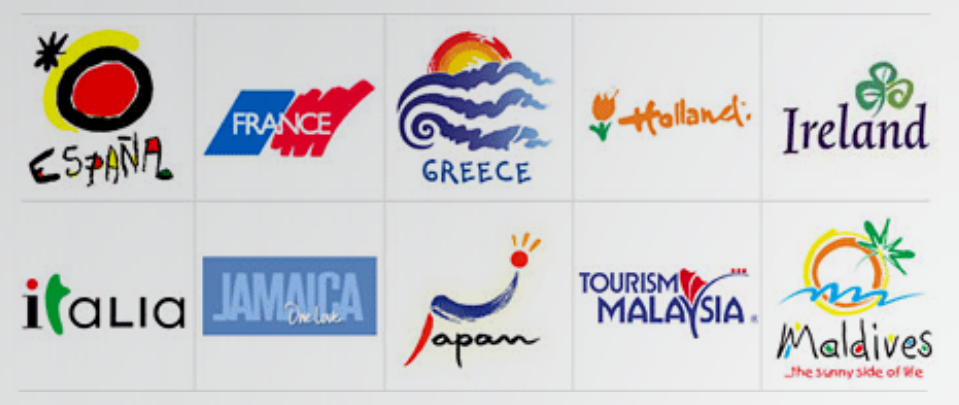

Aunque lograr acuerdos unánimes en procesos de esta naturaleza puede resultar muy poco probable, un trabajo "consciente" de investigación para el diseño centrado en las personas, puede evitar que la identidad visual creada y comunicada no necesariamente represente a las personas, colectivos o comunidades provocando conflictos o divisiones, donde resulta mayor el perjuicio que la solución.

Así mismo, construir memoria es un acto político y una práctica social. Los relatos y en ellos la relevancia de la visualidad a la que el furor de los "estudios visuales" le dio protagonismo como documento histórico, son oportunidades para que el diseño participe en el reconocimiento de las identidades sociales y culturales, visualice escenarios para el reconocimiento de las afinidades y diferencias, los sucesos, las posturas, las legitimidades y demás tensiones que configuran la cultura de una sociedad.

\subsection{DISEÑO GRÁFICO Y COMUNICACIÓN}

La comunicación es el inicio de la mayoría si no de todas - las acciones sociales, pues se constituye como el punto de encuentro de las personas, en el cual las mismas pueden descubrirse, construirse y reconstruirse como colectivo y como seres individuales. Comunicar es designar, dotar de sentido y diseñar-discursos visuales- es una búsqueda de acciones eficaces desde el dominio de la comunicación que involucran una construcción semántica, sintáctica y pragmáticamente congruente en función de una intención comunicativa en las diferentes escalas.

Para garantizar su pertinencia, estos discursos se construyen en función del reconocimiento de los procesos perceptivos, cognitivos y mentales de los destinatarios, la recuperación de sus códigos, el conocimiento de sus acuerdos previos y la claridad acerca del contexto y la circunstancia en que los mensajes diseñados serán el punto de confluencia entre emisor y destinatario para que la intención comunicativa se cumpla (Alvarez, 2009, pág. 106). 
Sin embargo, describir los procesos de comunicación bajoel concepto de emisoryreceptor como extremos de la comunicación -concepto derivado de la informática-, es inadecuado en tanto implicaría desconocer diferencias de estilos cognitivos, culturas, expectativas, sentimientos, intenciones, sistemas de valores y niveles de inteligencia. Los mensajes que producimos no solo son recibidos, sino que son interpretados por las personas; pero no solamente deben ser entendidos o interpretados sino que deben llevar a una determinada acción: encontrar la salida en un recinto, armar las conexiones de un equipo, completar un formulario, preparar una receta (Frascara, 2011).

«...allí donde hay comunicación hay diseño gráfico. Al igual que la comunicación, este se encuentra en todas partes» (Julier, 2010) en la cultura del diseño.

\subsection{DISEÑo PARA LA RELACIÓN: PERSONAS - ENTORNOS, TERRITORIOS}

Encontrar un consultorio dentro de un hospital, los baños en un centro comercial, la información turística en un sitio que se visita, los recorridos en un jardín botánico o en un parque urbano, el ascensor en un edificio inteligente, la plataforma de embarque en el aeropuerto, comprender el panel de información del sistema de transporte masivo o de un museo, conducir en la ciudad entre cientos de ejemplos- pueden convertirse en un ejercicio frustrante cuando la mediación visual no ha sido la adecuada.

Diseñar para la relación de las personas con su entorno, aunque es también una actividad que requiere necesariamente el concurso interdisciplinar ha sido sistemáticamente descuidada por el diseño, por dar prelación a "satisfacer las «necesidades» cuidadosamente elaboradas y manipuladas que inculcan la moda y la novedad" (Papanek, 1973).

Entender la complejidad de la experiencia humana no es un trabajo sencillo, diseñar objetos que solucionen problemas cotidianos como la movilidad, la protección contra el frío, artículos que faciliten actividades diarias, entre otros, requieren de estudios que si bien es cierto son rigurosos y han logrado los propósitos para los que fueron creados, encuentran límites con otras necesidades humanas ya que diseñar en pro de soluciones que abarquen las necesidades psicológicas, espirituales e intelectuales de un ser humano suelen ser más difíciles de cumplir. [...] Durante los últimos tiempos, el diseñador ha satisfecho solamente necesidades y deseos pasajeros, descuidando las verdaderas necesidades del hombre (Op.cit., 1973).

Conocer en profundidad al "usuario", entender cómo desarrolla sus actividades, qué lenguaje y códigos utiliza, cuáles son sus conocimientos previos en relación al tema en cuestión, cuáles son sus prácticas en la búsqueda de información, con qué recursos cuenta para la búsqueda, su familiaridad con ciertos esquemas, diagramas o mapas, el manejo de cierto software, si cuenta con teléfonos inteligentes, si tiene conectividad a internet y una aproximación a su uso, son solo algunos de los factores a considerar en un proceso de diseño para la relación de las personas con los entornos (Departamento de Estudios Tipográficos DET, 2014).

En estos casos, el "usuario" se define como la persona que utilizará la información que se intenta comunicar y no significa lo mismo que "cliente" o "consumidor". El énfasis de la investigación de mercado y el de la investigación de usuarios son sustancialmente distintas. La primera segmenta a la población en perfiles relacionados con sus conductas a la hora de consumir o comprar un producto o servicio. La investigación de usuarios, en cambio, se centra en cómo la persona utiliza la información para realizar una acción determinada, y está íntimamente relacionada con el contexto de cada individuo, por lo que no pueden definirse categorías universales de análisis para determinar sus perfiles.

El diseño gráfico tiene un radio de corresponsabilidad quizás más amplio de lo que se sospechaba. Para citar un ejemplo, se toma el caso de una investigación doctoral realizada en el Masivo Integrado de Occidente MIO en Cali, Colombia que analiza el cambio del transporte colectivo al sistema de transporte basado en BRT, desde la perspectiva del diseño de información considerando que pasados dos años de su implementación no ha logrado la percepción esperada en sus usuarios, y expone como una de sus conclusiones:

[...] La movilidad, como una dinámica humana, y la infraestructura, como su interfaz, requieren una forma de articulación de diferentes factores: las capacidades corporales (física, mental, intuitiva), la reducción de complejidades tales como la contaminación visual o física, la planificación previa y un enfoque de diseño claro, la experiencia previa con sistemas similares de información y capacitación en nuevos sistemas y, por último, 
el uso apropiado de canales de divulgación y presentación de información para ayudar en el proceso (Uribe, 2014).

En el mundo moderno, en el contexto de la circulación internacional y las dinámicas potenciadas por las fuerzas productivas, señalizar y orientar los recorridos tanto en entornos físicos como digitales, el diseño gráfico tiene una responsabilidad mayor a la de guiar los recorridos de lectura o la navegación de contenidos, es la de plantearse qué efectos tendrán sus artefactos, qué capacidad tienen de convocar a una convergencia cultural y de incidir en las situaciones que cada momento histórico genera.

\subsection{DISEÑO PARA LA RELACIÓN PERSONAS - MENSAJES, INTERFACES, PRODUCTOS}

La noción de diseño centrado en las personas parte del supuesto que el objetivo de diseño no es la producción de objetos, sino la generación de reacciones deseadas en la gente, y en esa simbiosis juega el concepto de usabilidad.

[...] Todo proyecto se destina a un usuario. Todo proyecto, por menos relevante que sea, debe relacionarse con alguien de alguna forma. Lo mismo que los proyectos que son abiertamente desconsiderados o incluso aquellos que agreden a sus usuarios implican el deseo de ser vistos o usados; el usuario nunca está ausente. La usabilidad es, por lo tanto, una característica inherente al diseño, no una cuestión específica y tendría, consecuentemente, la misma complejidad que el propio diseño. (Stolarski, 2009, pág. 83)

En este sentido, debe entenderse que el problema central del diseñador gráfico de mensajes, interfaces y productos, en su capa gráfica, es la creación de medios que sirvan a la gente para aprender, recordar, actuar, interactuar (con objetos, gente e información), realizar sus deseos y satisfacer sus necesidades. (Frascara, 2011). El diseño actúa como creador de hábitos cognitivos, con la tarea no solo de facilitar la gestión de la vida cotidiana, sino también de educar a través de la promoción de ciertas estructuras visuales que están asociadas a los sistemas de valores.

\subsection{EL DISEÑO DE INFORMACIÓN}

El diseño de información tiene como objetivo asegurar la efectividad de las comunicaciones mediante la facilitación de los procesos de percepción, lectura, comprensión, memorización y uso de la información presentada. Es necesariamente diseño centrado en el usuario. Es ético, porque la ética se basa en el reconocimiento del "otro" como diferente y respetable en su diferencia. (Frascara, 2011, pág. 9)

Las áreas, al margen de la publicidad para el consumo y el entretenimiento, en las que la acción del diseño gráfico es trascendente en el bienestar de las personas en su relación con mensajes, interfaces y entornos son diversas y casi siempre cotidianas: agenda o programación de eventos y servicios, manuales de instrucciones: aparatos, medicamentos, productos electrónicos, electrodomésticos, reglas de juego; señalización: símbolos, carteles, señales y sistemas; mapas y planos (sin llegar a la especialización de cartografía, arquitectura o ingeniería que son problemas de diseño de comunicación visual no enfrentados por diseñadores gráficos); libros escolares, informes técnicos, gráficos y diagramas para visualizar información de trabajo; documentos científicos, directorios, horarios, material didáctico; empaques; documentos administrativos: formularios, boletos, entradas; catálogos: programas, prospectos, exposiciones; interfaces para medios electrónicos; interfaces de comunicación interna en las organizaciones, paneles de control (sistemas de sonidos, cabinas de comando); todo esto posible en medios impresos, electrónicos, tridimensionales, fijos, en movimiento, pasivos, interactivos, etc.

Cuando el diseño de estos productos no se ha hecho con la responsabilidad y conciencia que les es pertinente, se produce un mayor esfuerzo cognitivo, errores en la comprensión de la información, materiales educativos o informativos que en vez de invitar causan rechazo, información técnica ambigua, formularios que generan error, sitios web confusos, cansancio excesivo en quienes operan sistemas o paneles de control, entre otros, todo esto causando pérdida de tiempo, frustración y hasta peligro, en contravía a lo se pueda considerar como bienestar humano. Adicionalmente, este esfuerzo tiene un costo en eficiencia, y lo que de esta se deriva, para las entidades y organizaciones: los procesos toman más tiempo o exigen reprocesos permanentes, están más expuestos a errores, demandan contratar más personal para explicar lo que los productos gráficos no lograron y producen más fatiga en los usuarios finales. 
Sin embargo, esta no es una tarea exclusiva del diseño gráfico, lo cual no lo exime de su responsabilidad. En estos procesos, lo ideal es tener el concurso de las disciplinas implicadas en el contenido del producto de diseño: la ergonomía, la lingüística, la psicología (perceptiva, cognitiva, emotiva, del desarrollo de la educación y de la conducta), la sociología (cultura, demografía, estadísticas, encuestas), la antropología (observación etnográfica y teoría de la cultura), las ciencias de la computación, entre otras, siempre atentos a las particularidades de cada caso desde la perspectiva de los usuarios.

$\mathrm{Y}$ aunque el reto consiste en hacer inteligible a los lectores una organización de datos, códigos e información, para lo cual es imprescindible un tratamiento tipográfico impecable [macro y micro] según las particularidades del proyecto, muchas veces los juicios sobre el diseño se hacen en función de los detalles de la apariencia, la factura, la técnica y no del contenido, su estructuración y su razón de ser. Como lo expresa Zenaida Osorio (2010):

[...] El interlineado nunca ha sido el motivo para leer: las personas leen y escriben por razones más humanas. Mujeres y hombres leen instrucciones, catálogos, carteles, periódicos, tarjetas, novenas o directorios, porque necesitan el salario de un trabajo, porque están enamoradas, porque su vida pende del cobro de una pensión, porque quieren proteger a un hijo víctima del abuso sexual, porque necesitan encomendarse a su santa patrona, porque urgen de la ayuda que les ofrece una institución del estado, porque a solas necesitan aplicar una prueba de embarazo. Las personas usan las letras para protestar contra un grupo violento, molestar a la vecina, dejar de repetir el precio y el nombre de una fruta impronunciable, prometer las mejores morcillas y chorizos, divulgar entre sus colegas datos recientes, conducir un camión por una autopista, presentar un proyecto para obtener financiación, saber dónde están paradas en este momento, o saber de cuánto es el billete que le robaron.

Es esta una reflexión para recordar el verdadero sentido del diseño gráfico, que está abriendo los ojos a descubrir que no son las fórmulas, son las personas.

\subsection{EL COMPONENTE EMOCIONAL DE LA EXPERIENCIA}

Morales (2005), expone que en los últimos años se ha hablado de un diseño de la experiencia o diseño "experiencial", para referirse a la vivencia del usuario con la propuesta de diseño. Aclara que no se trata de "diseñar experiencias" sino objetos, interfaces o espacios que influyan en la experiencia vivida por el usuario a partir de sus características particulares. Citando a Elizabeth Sanders, afirma que puede diseñarse para una experiencia, más no la experiencia como tal.

Desde el diseño positivo, Desmet y Hekkert (2007) proponen un marco conceptual de la experiencia con el producto, que aplica para las respuestas afectivas que podrían ser experimentadas en la interacción de los seres humanos con los productos. Este marco incluye tres componentes: la experiencia estética (el grado en el cual todos los sentidos se ven gratificados), la experiencia de significado (la carga personal o simbólica que un producto puede representar a través de procesos cognitivos como la interpretación, la recuperación de la memoria y la asociación) y la experiencia emocional (que involucra las experiencias típicas de la psicología emocional y del lenguaje cotidiano, suscitadas por la valoración del significado relacional de los productos) (Diseño positivo, guía de referencia, 2016, pág. 33).

Este marco potencia diversas posibilidades en la ideación de discursos visuales para el bienestar humano. Por citar solo algunos: tipos de placer con el producto: físico, social, psicológico, ideológico (p.45); diseño para el bienestar considerando los roles del diseño: como fuente, como símbolo, como mediador y como apoyo (p. 51); oportunidades de diseño para el bienestar según la fuente, el enfoque y la dirección, generando productos y/o actividades significativas (p.55); el apego por el producto, es decir el diseño para la durabilidad emocional, según el cual el usuario puede acercarse a través de cuatro posibles determinantes: la expresión personal, la afiliación grupal, el placer y los recuerdos (p.61), quizás un empaque o un libro pueden ejemplificar este concepto.

Pieter Desmet en 2003, propuso cinco categorías que aúnan respuestas emocionales que generan los productos en las personas y son: 
1) Emociones instrumentales: se refieren al resultado de la percepción del usuario al satisfacer metas que el producto debe cumplir. Satisfacción, decepción y frustración son tipos de emociones generadas tras la realización de una tarea por ejemplo.

2) Emociones estéticas: son aquellas que determinan el potencial de agrado del producto por parte del usuario. Esa capacidad de atraer u ofender los sentidos de la persona. Un tipo de emoción en este punto sería atracción o disgusto.

3) Emociones sociales: se presentan tras la evaluación de un producto en relación a lo que los demás observan y piensan tras el uso. Un ejemplo de esto sería tener algo que la gente puede llegar a desear o que le confieren admiración, status o envidia al usuario del objeto.

4) Emociones que evocan sorpresa: son aquellas que tratan con la percepción de lo que es nuevo.

5) Interés: posibles a través del desafío combinado con la promesa. La idea central de este tipo de emoción planteada, está centrada en la aceptación o rechazo del usuario frente al producto. (Van Hout, 2006)

\subsection{EL DISEÑO GRÁFICO EN LA INVESTIGACIÓN CENTRADA EN LAS PERSONAS}

En los encargos de diseño, el punto de partida no siempre acierta en lo que se necesita solucionar. Se parte de certezas parciales así que el primer reto para el diseñador es descubrir todo lo posible acerca del planteamiento inicial. Paul Hekkert [11] razonando acerca del valor de la investigación para el diseño centrado en las personas, expone cómo las herramientas, métodos, tendencias e incluso técnicas para empatizar pueden no ser suficientes para que los diseñadores descubran a profundidad lo que necesitan saber de las personas para orientar su trabajo. Los datos y las descripciones genéricas pueden llevar a soluciones convencionales, pero descubrir lo que las personas sueñan, sienten, cómo actúan y por qué es descender al reconocimiento de los principios que gobiernan el comportamiento, el cómo le dan sentido al mundo y de qué forma se suscitan sus emociones. Estos insumos probablemente direccionarán la acción del diseño a alternativas de solución inesperadas pero confiables, asertivas y poderosas.
Aunque las ciencias sociales han aportado numerosas metodologías y técnicas para aproximarse a las personas en la que conocemos como investigación de campo, el diseño y el pensamiento visual pueden incluirse en sí mismos como otro método (Morales, 2005), pues lo predominantemente visual despliega una enorme gama de posibilidades para la recolección de datos, para la propia experiencia de contacto y activación de sentimientos y memorias, e incluso para la visualización de todo el material previo al proceso de ideación y para la socialización con quienes toman las decisiones sobre políticas de alto nivel.

La verdadera inspiración para aportar soluciones significativas desde el diseño está en los mismos usuarios, pero encontrarla es el nuevo reto del diseño: ser herramienta, proceso y mediador para suscitar que revelen sus experiencias, ilusiones, emociones, rituales y estados ideales de relación con el mundo en los contextos de estudio específicos. La carga de la visualidad es absolutamente relevante en este proceso y puede hacer la gran diferencia, articulada con procesos estructurados, sistemáticos y conscientes opuestos a la improvisación denominada a veces experticia con la que son alcanzadas cotidianamente las soluciones a la reducción de deficiencias.

El pensamiento visual se incorpora como una herramienta de prefiguración, facilitando la visualización de las ideas, imbricándose en la apuesta por la proyectación y como parte del planteo, programación, modelación de ideas y conceptos, en el marco de un proyecto. De igual manera, mejora sustancialmente las comunicaciones de los proyectos, ya que permite implementar instrumentos como mapas mentales, mentefactos y bocetos, para explicar y visualizar las posibles definiciones y soluciones de los problemas, permitiendo el abordaje desde una perspectiva no lineal y creando otras alternativas a la resolución de estos. Así mismo, es útil para componer y descomponer, para evaluar alternativas dentro de las diferentes fases del proyecto, lo que hace del pensamiento visual un instrumento poderoso, fomentando el trabajo en equipo, convirtiendo el proyecto en un espacio participativo y horizontalizado. 


\section{A MANERA DE REFLEXIÓN FINAL}

Varios aspectos llaman la atención sobre el marco de referencia aquí planteado.

El encargo. Desde el mismo inicio del proceso de diseño, cuando se produce el "encargo" bien sea por iniciativa de un cliente, de un profesor o propia, intervienen tantos factores como personas y son muchas veces invisibilizados quienes pueden ofrecer aportes realmente valiosos al proyecto. ¿Por qué? A pesar de la extensa literatura que hoy se encuentra sobre metodología de la investigación, design thinking, diseño centrado en las personas, etc. pocas son las iniciativas, en contraste con las que privilegian objetivos de consumo, que quieren arriesgarse en términos de tiempo y otros recursos a diseñar procesos que respondan a lo expuesto sobre el bienestar humano.

Si bien el trabajo del diseñador se desarrolla muchas veces con parámetros determinados por otros dentro de un sistema que muchas veces no controla, es preciso hacer un llamado a la conciencia sobre su lugar en el mundo y la ética personal para su ejercicio profesional (Margolin, 2009). En este sentido, una alternativa que parece empezar a tomar fuerza es el autoencargo, es decir, un trabajo en el que los condicionantes y los objetivos del proyecto los establece el propio diseñador, y que, aunque parece cercano conceptualmente a algunos puntos de partida del arte, no necesariamente responde a una necesidad de expresión personal.

Es más bien, según Calvera (Arte ¿? Diseño: Nuevos capítulos para una polémica que viene de lejos, 2003, pág. 11) la oportunidad de "reemplazar al encargo que debiera darse y no se da por razones de índole social y económica. Entonces el autoencargo es para el diseñador una compensación ideológica surgida en el plano de la ética". Para Pelta, (2015, pág. 60) algunos diseñadores recurren al autoencargo para expresar lo que piensan y sienten ante determinadas situaciones $y$, por tanto, para ofrecer una vía alternativa a unos medios de comunicación a los que, dado el contenido inconformista de sus mensajes, tienen difícil acceso. $Y$ así protestan, denuncian y/o llaman a la acción, porque entienden que el diseño -con el debate que abrió el First thing first, es una herramienta poderosa que, lo mismo que puede persuadir a la gente para que compre productos, puede movilizar su conciencia.
No puede desconocerse que visto desde lo administrativo, además de la satisfacción personal y profesional que representa alinearse con las buenas acciones, surgen preguntas sobre aspectos relevantes en la operación como son el tiempo/dinero invertidos en los proyectos, y la disposición de quienes encargan en creerle a estas iniciativas. En culturas donde lo urgente supera a lo importante, donde el criterio que más pesa es el de la economía, donde se considera subjetivo o poco relevante el bienestar de las personas si se minimizan los problemas o deficiencias, puede tardar un poco comprender que el diseño deja de ser un fin, para convertirse en herramienta, proceso y solución de problemas y de retos de mayor trascendencia a los mismos.

Los criterios para producir y juzgar cualidades formales vs. el contenido y el sentido. La tradición del oficio y de las escuelas de diseño gráfico inclinadas a "imitar al maestro", "complacer al cliente", "copiar los referentes" en países en vía de desarrollo o de "periferia" como lo ilustrara Bonsiepe, son vulnerables a la influencia de las tendencias y las dinámicas del "centro" y esto ha creado en cierta manera una cultura de la solución prestada - preferiblemente rápida y descrestante, sin profundizar en las verdaderas razones que debieran suscitarla.

Los insumos y los productos del diseño gráfico son altamente sensibles en términos de simbolismos, destilación de valores y significados (Badosa \& Subirats, 2007), usos e interacciones que modifican las tensiones tanto en la cotidianidad como en el espacio público y pertenecen únicamente a grupos configurados con afinidades de diversa índole, por tanto le son pertinentes solo a estos y solo en condiciones particulares, que no les pueden ser impuestas las soluciones de otros. ¿Qué sentido tienen entonces las soluciones espectaculares si no han empatizado con sus usuarios finales? Lamentablemente, seguimos en esa dinámica tanto en la academia como en la industria, con juicios sesgados desde el gusto personal, en diseñadores, clientes, profesores, y no con criterios serios de diseño y evaluación de las propuestas que tengan en cuenta no solamente la capa gráfica de los discursos visuales, sino su contenido, su esencia y su sentido en el entorno de uso final.

[...] Es importante reflexionar sobre lo que ha sido y lo que debería ser. Las expresiones acerca de las cualidades del diseño deberían despojarse de la idea de envoltura estética y ornamental para introducir la idea de la materialización de creaciones 
útiles a partir de los recursos de la ciencia y de la tecnología para componer el ambiente artificial de los seres humanos. (Ramírez, Lecuona, \& Cardozo, 2012)

Para lograr solucionar esos problemas de manera competente hay que saber situarlos adecuadamente en el entramado de las relaciones y proyectos sociales, además de conocer y evaluar las variables de los materiales, las constructivas, de estandarización, de producción de distribución, de transporte, de reciclado, de ergonomía, de legibilidad, de motivación, etc. Algo más que un ejercicio de estilismo. Lo que ocurre es que todo eso frecuentemente se oculta. Conocemos los espectaculares desfiles de la moda y no el sistema industrial que ha de desarrollar el pret-àporter. Conocemos la ilustración fantasiosa y no el sistema editorial con sus trastiendas de producción y distribución, conocemos los logotipos y no la estructuración de programas de representación eficaces $y$

progresivos.

(González, 2006)

\section{El concepto de} evaluación parece entenderse desde los juicios, los gustos - las calificaciones y aún es incipiente la cultura de evaluar lo que consiguen los artefactos $y$ discursos visuales con los usuarios finales, en términos del propósito que motivó el proyecto.

Para un juicio ponderado acerca de la función de una actuación de diseño en concreto habría que tener presente un mapa con todo un conjunto de variables jerarquizadas y referidas tanto a centros como a periferias y a las diversas culturas, de manera que pudiéramos marcar un punto que nos dijese "Usted está aquí" [12], para de ese modo evitar la dogmatización y absolutización de posiciones parciales y reductivas propias de espacios psicoindividuales y no específicamente sociales. La historia, la estructura conceptual y la observación de la realidad (la práxis) esforzadamente desalienada, han de confrontarse continuamente en la definición de una labor y su función, en este caso el diseño. (González, 2006).

Salir del "yo diseñador" y pasar a la inter y transdisciplinariedad. Validar el peso de la participación interdisciplinar en un ejercicio de diseño hace parte de las competencias que requerimos para las dinámicas del siglo $\mathrm{XXI}$, cuando se demanda permanentemente por innovación y se agotan los discursos de la creatividad per se. El diseño tiene aún un largo camino por recorrer en esta dinámica de influenciar positivamente la vida cotidiana de las personas, al margen de alentar al consumo de productos y servicios. La investigación para el diseño centrado en las personas y las soluciones para el bienestar humano, ponen nuevamente de manifiesto la vigencia de lo "experiencial" incluso del otro lado de la moneda, desde quienes trabajamos para diseñar objetos, interfaces, espacios que infuyan desde una perspectiva positiva en los comportamientos, emociones y pensamientos de las personas en función de su bienestar.

Los desafíos políticos. Los discursos visuales generados por la práctica del diseño siempre evidencian en mayor o menor fuerza posiciones políticas por cuanto se gestan, se desarrollan y se usan en el mundo de lo simbólico, lo cognitivo, lo emotivo. El diseñador nunca es, ni debe serlo, un intermediario al margen, no puede ni debe refugiarse en un hipotético neutralismo técnico (Badosa \& Subirats , 2007). Desde las figuras del encargo, del autoencargo o de posiciones intermedias, el llamado al diseño consciente debería estar presente de manera permanente provocando retos a nuestras propias maneras de hacer $y$ atreviéndonos a trasladar a estos terrenos las convencionalidades de nuestro ejercicio, teniendo a la investigación en este caso centrada en las personas, como la aliada principal.

Encuentro tres formas en que el diseñador puede aportar su talento a la cultura: La primera es diseñando, es decir, haciendo cosas. El segundo es articulando una crítica de las condiciones culturales que explique los efectos del diseño en la sociedad, y el tercero es comprometiéndose políticamente. Hay demasiado poder que involucra al diseño en todas sus áreas que está en las manos equivocadas y sólo puede contrarrestarse con estrategias de acción bien pensadas. (Margolin, 2009)

En el presente, en el campo del diseño carecemos de un cuerpo de literatura que evalúe nuevos productos en todas sus dimensiones, sobre todo en las que se relacionan con el bienestar físico y emocional del público que las usa. [...] Ninguna persona que se dedica a la práctica del diseño debería poder hacer lo que quiera sin una respuesta de la sociedad a sus actos. La investigación sobre el diseño puede contribuir al debate sobre lo que debe diseñarse en el futuro. Hace falta más discusión pública sobre lo que se necesita en la sociedad y los investigadores deberían ser capaces de producir conceptos y 
prototipos de productos, sistemas y medios nuevos que puedan ser socialmente útiles. (Margolin, 2005)

El diseño para el bienestar humano no es una tendencia o una moda, es su esencia y su naturaleza sumadas a las condiciones básicas mínimas de usabilidad según los fines previstos. Con un mínimo de responsabilidad sobre lo que hacemos, debería ser así y no de otra manera aunque la herencia del oficio y las convenciones socio culturales sobre la profesión aún no lo ven tan claramente. El enorme poder político que el diseño gráfico puede alcanzar en las dinámicas contemporáneas es directamente proporcional a la responsabilidad con la que lo asumimos y a las consecuencias del mismo.

\section{REFERENCIAS}

- AIGA. (2015). AlGA.org. Recuperado el 20 de noviembre de 2016, de Designer of 2015 competencies: http://www.aiga.org/ designer-of-2015-competencies

- Alvarez, D. (2009). El diseño gráfico hecho por personas para las personas. En V. autores, El diseño y sus usuarios: de la forma a la interacción (págs. 105-116). México: Encuadre.

- Badosa, J., \& Subirats , J. (2007). ¿Qué diseño para qué sociedad? Notas sobre la funcionalidad social del diseño. Elisava TdT Temes de disseny(24), 35-41.

- Barrera, G., \& Quiñones, A. (2009). Diseño socialmente responsable. Bogotá: Pontificia Universidad Javeriana.

- Berman, D. B. (2015). Haz el bien diseñando. Cómo el diseño puede cambiar el mundo. . (J. E. Correa, Trad.) México: Designio.

- Betancourt, M. X. (2014). De la identidad social, a la Representación visual, Estrategias de Intervención Desde el diseño responsable. Kepes, 11(10), 281301.

- Calvera, A. (2003). Arte ¿? Diseño: Nuevos capítulos para una polémica que viene de lejos. Barcelona: Gustavo Gili.

- Castellanos, A., \& Otros. (2017). Modelo de gestión proyectual E10. Bogotá: Fundación Universitaria Los Libertadores.

- Chaves, N. (2001). El oficio de diseñar: propuestas a la conciencia crítica de los que comienzan. Barcelona: Gustavo Gili.

- Chaves, N. (2016). Acerca de la calidad gráfica. En L. F. Irigoyen, Extendiendo el espectro temático del diseño. México: Quartuppi.

- De Valle, C. (2009). Usabilidad: percepción e interpretación. En V. autores, El diseño y sus usuarios: de la forma a la interacción (págs. 133-143). México: Encuadre.

- Departamento de Estudios Tipográficos DET. (2014). 12 años del DET, el diseño que pasa inadvertido. Santiago de Chile: Pontificia Universidad Católica de Chile.

- Desmet, P., \& Pohlmeyer, A. (2013). Positive design: an introduction to design for subjetive well-being. International Journal of Design, 7(3), 5-19.

- Frascara, J. (2008). Diseño gráfico para la gente. Comunicaciones de masa y cambio social. Buenos Aires: Ediciones Infinito.

- Frascara, J. (2011). ¿Qué es el diseño de información? Buenos Aires: Ediciones infinito.

- Garone, M. (2001). Las diferencias entre diseño como arte aplicado, como ciencia y como herramienta de comunicación. En Antología del Diseño 1. México: Designio.

- González, J. (2006). El lugar del diseño en nuestra sociedad. Lugares de debate conceptual. (U. C. Madrid, Ed.) Recuperado el 08 de mayo de 2017, de http://pendientedemigracion.ucm.es/ centros/cont/descargas/documento3049. pdf

- Hernández, M. (2009). El diseño gráfico como acto hermenéutico. En V. autores, El diseño y sus usuarios: de la forma a la interacción (págs. 155-165). México: Encuadre.

- Heskett, J. (2005). Diseño en la vida cotidiana. Barcelona: Gustavo Gili.

- IDEO.org. (2015). Diseño centrado en las personas. Kit de herramientas. ( $2^{\mathrm{a}}$ ed.). San Francisco: IDEO.

- Jimenez, S., Pohlmeyer, A., \& Desmet, P. (2014). Learning from de positive: a structured approach to possibility-driven design. En J. Compiladores: Salamanca, \& Otros, The colors of care: International Conference on Design and Emotion (9th : 2014 : Colombia) (págs. 607-615). Bogotá: Ediciones Uniandes.

- Jiménez, S., Pohlmeyer, A., \& Desmet, P. (2016). Diseño positivo, guía de referencia. (J. F. Merino, Trad.) Bogotá: Ediciones Uniandes.

- Julier, G. (2010). La cultura del diseño. Barcelona: Gustavo Gili, SL. Colección 
GG Diseño, Barcelona, España.

- Margolin, V. (2005). La investigación sobre el diseño y sus desafíos. En V. autores, Las rutas del diseño (págs. 9-31). México: Editorial Designio.

- Margolin, V. (02 de febrero de 2009). El diseñador ciudadano. Recuperado el 20 de marzo de 2017, de ForoAlfa: https://foroalfa.org/articulos/el-disenadorciudadano

- Morales, E. (2005). La metodología en la investigación del diseño y el diseño como método de investigación. En V. autores, Las rutas del diseño. Ensayos sobre teoría y práctica (págs. 69-81). México: Editorial Designio.

- NASAD. (7 de noviembre de 2016). National Association of Schools of Art and Design. Obtenido de Handbook 201617: https://nasad.arts-accredit.org/wpcontent/uploads/sites/3/2015/11/NASAD_ HANDBOOK_2016-17.pdf

- Norman, D. (2004). El diseño emocional: por qué nos gustan (o no) los objetos cotidianos. Barcelona: Ediciones Paidós Ibérica S.A.

- Osorio, Z. (2010). El interlineado nunca ha sido el motivo para leer. En M. (. Cárdenas, La escuela hoy. Foro permanente La Escuela de Diseño Gráfico y su Realidad Académica (págs. 50-58). Bogotá: Universidad Nacional de Colombia.

- Papanek, V. (1973). Diseñar para el mundo real. Ecología humana y cambio social. Madrid: H. Blume Ediciones.

- Pelta, R. (2012). Diseñar para el cambio social. Recuperado el 18 de marzo de 2017, de Monografica.org: http://www. monografica.org/02/Opini\%C3\%B3n/3112

- Pelta, R. (2015). Diseñar hoy. Temas contemporáneos del diseño gráfico. Barcelona: Paidós.

- Pontis, S. (2010). Para qué sirve investigar en diseño. Obtenido de ForoAlfa: https:// foroalfa.org/articulos/para-que-sirveinvestigar-en-diseno

- Ramírez, N., Lecuona, M., \& Cardozo, J. (Enero-junio de 2012). Diseño y bienestar humano: puntos de encuentro a partir de metodologías de diseño. Iconofacto, 8(10), 88-114.

- Stolarski, A. (2009). Cuatro usuarios y la otra usabilidad. En V. autores, El diseño y sus usuarios: de la forma a la interacción (págs. 83-90). México: Encuadre.
- Tapia, A. (2005). El diseño gráfico en el espacio social. México: Designio.

- Uribe, M. (2014). Diseño de información: mediador entre la tradición oral y la esfera digital en el transporte público. Caso del Masivo integrado de Occidente Cali - MIO . Iconofacto, 10(14), 51-75.

- Van Hout, M. (5 de Noviembre de 2006). Getting Emotional With... Pieter Desmet. Obtenido de Design \& Emotion: http:// www.design-emotion.com/2006/11/05/ getting-emotional-with-dr-pieter-desmet/

- Van Hout, M. (julio de 2008). Comprendiendo, midiendo, diseñando (para la) emoción. Faz Revista de diseño de interacción(2), 89-95.

- Zaragozá, R., \& Gasca, J. (2014). Designpedia. 80 herramientas para construir tus ideas. España: LID Editorial.

\section{NOTAS}

[1] Aunque no es la primera vez que el diseño se hacía esta autocrítica. Desde antes de denominarse Diseño gráfico, el propio William Morris a finales del siglo XIX se refirió a aprender a ver más allá del engaño del orden, para entender el verdadero carácter de los dispositivos, de los sistemas y situaciones con y dentro de los cuales vivimos. Podría afirmarse que Morris fue uno de los primeros diseñadores ciudadanos y puede servir como un excelente ejemplo de cómo un diseñador puede comprometerse con la cultura de su época (Margolin, El diseñador ciudadano, 2009)

[2] Peters, C. \& otros. (2014). FIRST THINGS FIRST 2014. abril 6, 2015, de firstthingsfirst2014. org. Sitio web: http://firstthingsfirst2014.org/

[3] El Diseño gráfico entendido aquí en su noción contemporánea amplia en la que concierne a la configuración de discursos en lenguaje visual y audiovisual, fijos y en movimiento, pasivos e interactivos, impresos, para dispositivos de pantalla, y para aplicaciones arquigráficas entre otras, en el marco de la comunicación.

[4] La psicología positiva se define como el estudio científico de las experiencias positivas, los rasgos individuales positivos, las instituciones que facilitan su desarrollo y los programas que ayudan a mejorar la calidad de vida de los individuos, mientras previene o reduce la incidencia de la psicopatología (Seligman 2005; 
Seligman \& Csikszentmihalyi, 2000). Es definida también como el estudio científico de las fortalezas y virtudes humanas, las cuales permiten adoptar una perspectiva más abierta respecto al potencial humano, sus motivaciones y capacidades (Sheldon \& King, 2001), incluye también virtudes cívicas e institucionales que guían a los individuos a tomar responsabilidades sobre su comunidad y promueve características para ser un mejor ciudadano (Seligman \& Csikszentmihalyi, 2000).

[5] Delft Institute of Positive Design. Recuperado de http://studiolab.ide.tudelft.nl/diopd/about-us/.

[6] AIGA, American Institute of Graphic Arts es un colegio oficial de diseño gráfico creado en los Estados Unidos en 1914. Ahora, The professional association for design, es la organización de membresía profesional más antigua y más grande de la profesión para el diseño, con 70 capítulos y más de 25.000 miembros. Ver: http://www.aiga. org/

[7] Fundada en 1944, la Asociación Nacional de Escuelas de Arte y Diseño (NASAD) es una organizacióndeescuelas, conservatorios, colegios y universidades, con aproximadamente 360 miembros institucionales acreditados. Establece normas nacionales para títulos de grado y posgrado y otras credenciales para el arte y el diseño y disciplinas del arte / relacionados con el diseño, y proporciona asistencia a las instituciones y personas que participan en el arte / actividades artísticas, científicas, educativas, y otras relacionadas con el diseño. Ver: https:// nasad.arts-accredit.org/

[8] En Diseño Positivo Guía de referencia. Cap. 11 / Seis dimensiones del bienestar psicológico.

[9] En el presente documento no se profundiza en el entretenimiento o búsqueda del placer ni en las dinámicas de consumo, por considerar que se trata de campos específicos que merecen un tratamiento particular y sobre los que existen diversidad de reflexiones, discusiones y perspectivas. Tampoco sobre las características de técnicas, sustratos ni especificidades del lenguaje visual, ya que el interés se sustenta en el sentido del contenido de los discursos que genera el diseño gráfico.

[10]Valelapenaanalizardentrodeestaperspectiva Iniciativas como 99designs, plataforma de servicios de diseño gráfico creada en 2008 que funciona a través de crowdsourcing para que pequeñas y medianas empresas resuelvan sus necesidades de diseño gráfico, especialmente en creación de logotipos, envases, portadas de libros y camisetas entre otros, partiendo de un conocimiento incipiente y casi genérico de a quiénes pretende dotarse de identidad visual. Ver: https://en.99designs.com.co/

[11] Profesor de Teoría de la Forma en la Universidad Tecnológica de Delft, presidente de la Sociedad Internacional de Diseño y Emoción (Design and Emotion Society) y coautor de Vision in Design -A Guidebook for Innovators.

[12] GONZÁLEZ SOLAS, Javier: "Usted está aquí. Dos paradigmas para la crítica del diseño: lo público y lo privado". En III Simposio de Creatividad Publicitaria. Barcelona, marzo 2006. Publicado en Trípodos, extra 2006.

\section{Para citar este artículo:}

Gualdrón - Cantor, N. (2018). Diseño para el bienestar humano. El sentido y el contenido del discurso visual. Revista Luciérnaga / Comunicación. Año 10, N19. Págs. 91-109.

OJS. http://revistas.elpoli.edu.co/index.php/luc/issue/archive Link. http://www.politecnicojic.edu.co/index.php/revista-luciernaga 